\title{
Understanding the Reactivity of Planar Polycyclic Aromatic Hydrocarbons: Towards the Graphene Limit
}

\author{
Yago García-Rodeja, ${ }^{[a]}$ Miquel Solà, ${ }^{[b]}$ and Israel Fernández ${ }^{[a], *}$
}

[a] Mr. Y. García-Rodeja and Dr. I. Fernández

Departamento de Química Orgánica, Facultad de Ciencias Químicas, Universidad Complutense, 28040 Madrid (Spain)

Fax: (+34)913944310

E-mail: israel@quim.ucm.es

[b] Prof. Dr. M. Solà

Institut de Química Computacional and Departament de Química, Universitat de Girona, Campus Montilivi, 17071 Girona, Spain.

\begin{abstract}
The Diels-Alder reactivity of maleic anhydride to the bay regions of planar polycyclic aromatic hydrocarbons has been explored computationally within the Density Functional Theory framework. It is found that the process becomes more and more exothermic and the associated activation barriers become lower and lower when the size of the system increases. This enhanced reactivity follows an exponential behavior reaching its maximum for systems having 18-20 benzenoid rings in their structures. This peculiar behavior has been analyzed in detail using the activation strain model of reactivity in combination with the energy decomposition analysis method. In addition, the influence of the change in the aromaticity strength of the polycyclic compound during the process on the respective activation barriers has been also studied.
\end{abstract}

Keywords: Polycyclic Aromatic Compounds - reactivity - DFT calculations - Diels-Alder · Activation Strain Model 


\section{Introduction}

Polycyclic aromatic hydrocarbons (PAHs) are a large class of compounds that are composed of two or more fused aromatic rings. ${ }^{[1,2]}$ This particular family of organic compounds can be divided into two main subgroups, namely planar PAHs and bowl-shaped PAHs, the latter characterized by curved $\pi$-systems composed of pyramidalized carbon atoms ${ }^{[3,4]}$ Naphthalene, anthracene or perylene are therefore representative examples of planar PAHs, whereas corannulene, hemifullerene or circumtrindene belong to the bowl-shaped subgroup, also known as buckybowls or fullerene fragments. The relevance and properties of these species are manifold: on the one hand, PAHs, particularly those having lower molecular heights, exhibit a significant carcinogenic potency, ${ }^{[5]}$ while on the other hand, they present interesting and tunable optical and electrochemical properties which are highly useful in materials science. ${ }^{[6]}$ For these reasons, understanding the intrinsic reactivity of PAHs is of crucial importance not only to control the synthesis of novel PAHs with potential applications as organic materials but also their inherent toxicity.

Very recently, we focused on the factors governing the reactivity of bowl-shaped PAHs. ${ }^{[7]}$ By means of the combination of the Activation Strain Model (ASM) ${ }^{[8]}$ of reactivity and the Energy Decomposition Analysis (EDA ${ }^{[9]}$ method, it was found that for the Diels-Alder reaction with cyclopentadiene, starting from corannulene, there is a smooth convergence to the $\mathrm{C}_{60}$ energy barrier when the size of the buckybowl is increased. The observed trend of [4+2]reactivity of buckybowls was ascribed to the interplay between the deformation required to adopt the corresponding transition state (TS) geometry (major factor) and the interaction between the deformed reactants. ${ }^{[7]}$ This analysis has been also particularly useful to gain more insight into the regioselectivity of the process (i.e. preference for the [6,6]-bonds), a behavior which is also found in $\mathrm{C}_{60}$-fullenere ${ }^{[10]}$ and related systems. ${ }^{[11,12]}$

Interestingly, a similar reactivity trend (i.e. the reactivity increases with the size of the system) has been observed in planar PAHs as well. ${ }^{[13]}$ Indeed, the energy barrier for the Diels- 
Alder reaction of acetylene to the bay regions of planar PAHs in the periacene series (i.e. from phenanthrene to tetrabenzocoronene) was predicted by means of Density Functional Theory (DFT) calculations to steadily decrease with the size of the PAH. This computational prediction was experimentally confirmed as well. ${ }^{[13,14]}$ As shown in Scheme 1, whereas the Diels-Alder reaction involving 7,14-dimesitylbisanthene and diethyl acetylenedicarboxylate proceeds with complete conversion at $120{ }^{\circ} \mathrm{C}$ for $24 \mathrm{~h}$, a much lower $<50 \%$ conversion is observed for perylene, even when the reaction was conducted at $150{ }^{\circ} \mathrm{C}$ for $72 \mathrm{~h} .{ }^{[13]} \mathrm{A}$ similar behavior was observed in the reactions of these species with nitroethylene ${ }^{[15]}$ and previously by Clar and Zander in the harsh conditions required for the reaction of perylene and maleic anhydride $\left(202{ }^{\circ} \mathrm{C}\right.$ in the presence of chloranil). ${ }^{[16]}$ Interestingly, this Diels-Alder reaction of acetylene to the bay regions of PAHs was proposed as a chemical metal-free synthetic strategy to grow carbon single-walled armchair nanotubes. ${ }^{[13]}$
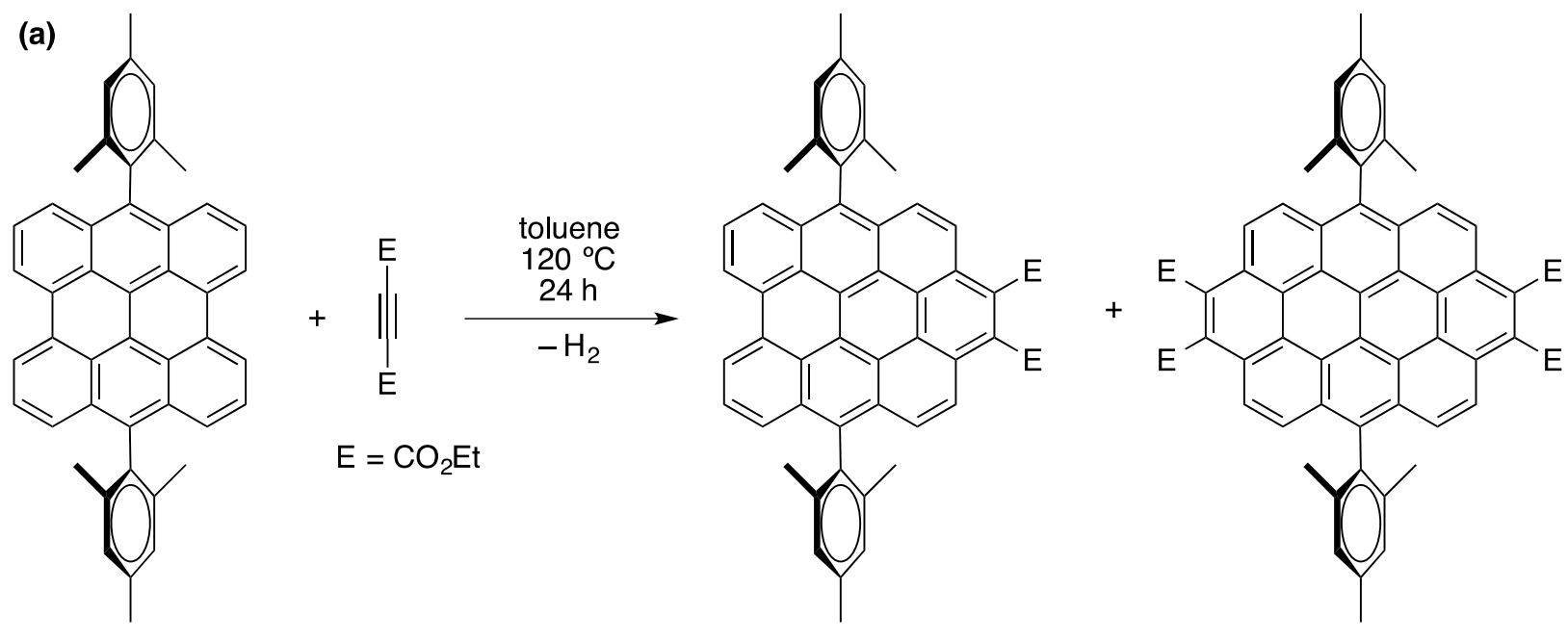

(b)

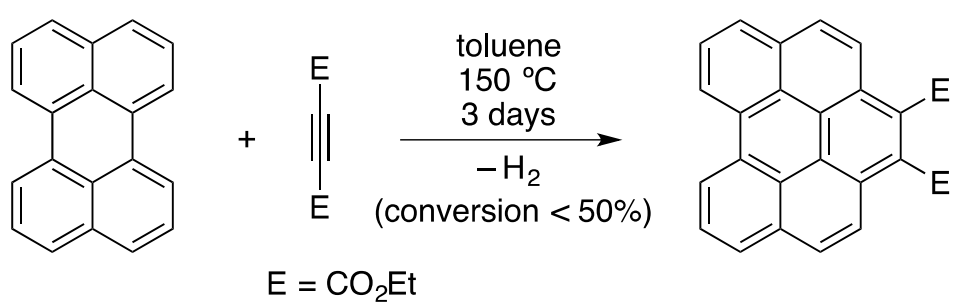

Scheme 1. Diels-Alder cycloaddition reactions involving 7,14-dimesitylbisanthene (a) and perylene (b). 
This improved reactivity has been traditionally attributed to the nature of the double bonds in the bay region of the molecule which, in principle, become more and more localized (i.e. resembling more and more 1,3-butadiene) with the size of the PAH. As a consequence, the reluctance of smaller members of the family to engage in bay region Diels-Alder cycloadditions has been ascribed, and qualitatively approximated, to the difference in the aromatic stabilization energies ( $\triangle \mathrm{ASE}$ ) between the starting PAH and the corresponding cycloadduct. ${ }^{[13]}$ Despite that, little is known on the physical factors controlling the intrinsic reactivity of this family of organic compounds which results in the above commented reactivity trend. For this reason, herein we decided to apply the combination of the ASM and EDA methods to planar PAHs in order to gain a quantitative understanding of those factors governing the Diels-Alder reactivity of these species. To this end, the [4+2]-cycloaddition reaction involving the bay region of different planar PAHs (see below) and maleic anhydride as dienophile was analyzed in detail and compared with our previous results on bowl-shaped PAHs.

\section{Theoretical Methods}

\section{Computational Details}

Geometry optimizations of the molecules were performed without symmetry constraints using the Gaussian03 $3^{[17]}$ optimizer together with Turbomole $6.6^{[18]}$ energies and gradients at the BP86 $6^{[19] / \text { def2-SVP }}{ }^{[20]}$ level of theory using the D3 dispersion correction suggested by Grimme et al. ${ }^{[21]}$ and the resolution-of-identity (RI) approximation. ${ }^{[22]}$ This level is denoted RI-BP86D3/def2-SVP and has been selected because it provides very good results for cycloaddition reactions involving related bowl-shaped $\mathrm{PAHs}^{[7]}$ and fullerenes. ${ }^{[10-12]}$ Reactants and cycloadducts were characterized by frequency calculations, and have positive definite Hessian matrices. Transition states (TSs) show only one negative eigenvalue in their diagonalized force constant matrices, and their associated eigenvectors were confirmed to correspond to the motion along the reaction coordinate under consideration using the Intrinsic Reaction Coordinate (IRC) method. ${ }^{\text {[23] }}$ Single-point energy refinements were carried out at the same DFT level using the triple- $\zeta$-quality 
def2-TZVPP basis sets. ${ }^{[20]}$ This level is therefore denoted BP86-D3/def2-TZVPP//RI-BP86D3/def2-SVP.

\section{Activation Strain Analyses of Reaction Profiles}

The activation strain model of reactivity, also known as distortion/interaction model, ${ }^{[24]}$ is a fragment approach to understanding chemical reactions, in which the height of reaction barriers is described and understood in terms of the original reactants. ${ }^{[8]}$ The ASM is a systematic extension of the fragment approach from equilibrium structures to TSs as well as non-stationary points, e.g., points along a reaction coordinate. Thus, the potential energy surface $\Delta E(\zeta)$ is decomposed, along the reaction coordinate $\zeta$, into the strain $\Delta E_{\text {strain }}(\zeta)$ associated with deforming the individual reactants plus the actual interaction $\Delta E_{\text {int }}(\zeta)$ between the deformed reactants:

$$
\Delta E(\zeta)=\Delta E_{\text {strain }}(\zeta)+\Delta E_{\text {int }}(\zeta)
$$

The strain $\Delta E_{\text {strain }}(\zeta)$ is determined by the rigidity of the reactants and by the extent to which groups must reorganize in a particular reaction mechanism, whereas the interaction $\Delta E_{\text {int }}(\zeta)$ between the reactants depends on their electronic structure and on how they are mutually oriented as they approach each other. It is the interplay between $\Delta E_{\text {strain }}(\zeta)$ and $\Delta E_{\text {int }}(\zeta)$ that determines if and at which point along $\zeta$ a barrier arises, namely, at the point where $\mathrm{d} \Delta E_{\text {strain }}(\zeta) / \mathrm{d} \zeta=-\mathrm{d} \Delta E_{\text {int }}(\zeta) / \mathrm{d} \zeta$. The activation energy of a reaction $\Delta E^{\ddagger}=\Delta E\left(\zeta^{\mathrm{TS}}\right)$ consists therefore of the activation strain $\Delta E_{\text {strain }}^{\ddagger}=\Delta E_{\text {strain }}\left(\zeta^{\mathrm{TS}}\right)$ plus the TS interaction $\Delta E_{\text {int }}^{\ddagger}=\Delta E_{\text {int }}\left(\zeta^{\mathrm{TS}}\right)$,

$$
\Delta E^{\ddagger}=\Delta E_{\text {strain }}^{*}+\Delta E_{\text {int }}^{*}
$$

In the cycloaddition reactions involving planar PAHs and maleic anhydride, the reaction coordinate is defined as the projection of the IRC on the forming $\mathrm{C} \cdots \mathrm{C}$ distance between the carbon atom of the PAH and the carbon atom of the anhydride. This reaction coordinate $\zeta$ undergoes a well-defined change in the course of the reaction from the initially formed reactant complexes to the equilibrium $\mathrm{C} \cdots \mathrm{C}$ distance in the corresponding TSs. Since some of the located 
concerted TSs are asynchronous, we have considered in all cases the shortest $\mathrm{C} \cdots \mathrm{C}$ distance as the reaction coordinate.

\section{Energy Decomposition Analysis}

The interaction $\Delta E_{\text {int }}(\zeta)$ between the strained reactants can be further partitioned with the help of the Energy Decomposition Analysis (EDA) method. ${ }^{[9]}$ Within this approach, this term is further decomposed into the following physically meaningful terms:

$$
\Delta E_{\text {int }}(\zeta)=\Delta V_{\text {elstat }}+\Delta E_{\text {Pauli }}+\Delta E_{\text {orb }}+\Delta E_{\text {disp }}
$$

The term $\Delta V_{\text {elstat }}$ corresponds to the classical electrostatic interaction between the unperturbed charge distributions of the deformed reactants and is usually attractive. The Pauli repulsion $\Delta E_{\text {Pauli }}$ comprises the destabilizing interactions between occupied orbitals and is responsible for any steric repulsion. The orbital interaction $\Delta E_{\text {orb }}$ accounts for charge transfer (interaction between occupied orbitals on one moiety with unoccupied orbitals on the other, including HOMO-LUMO interactions) and polarization (empty-occupied orbital mixing on one fragment due to the presence of another fragment). Finally, the $\Delta E_{\text {disp }}$ term takes into account the interactions which are due to dispersion forces.

The program package ADF 2014.01 ${ }^{[25]}$ was used for the EDA calculations at the BP86D3 level, in conjunction with a triple- $\zeta$-quality basis set using uncontracted Slater-type orbitals (STOs) augmented by two sets of polarization functions with a frozen-core approximation for the core electrons. ${ }^{[26]}$ Auxiliary sets of s, p, d, f, and g STOs were used to fit the molecular densities and to represent the Coulomb and exchange potentials accurately in each SCF cycle. ${ }^{[27]}$ Scalar relativistic effects were incorporated by applying the zeroth-order regular approximation (ZORA). ${ }^{[28]}$ This level of theory is denoted ZORA-BP86-D3/TZ2P//RI-BP86-D3/def2-SVP. 


\section{Results and Discussion}

Two related series of planar PAHs with armchair topology have been considered, namely series $\mathrm{A}$, having two bay regions and $3 n-1$ six-membered rings, and series $\mathrm{B}$, where the PAHs possess only one bay region and $3 n$ six-membered rings ( $n=1$ to 5 , Chart 1$)$. In all cases, the closed-shell singlet ground state is more stable than the corresponding triplet state with the notable exception of compound 9 ( $n=5$, series A) whose triplet ground state is $4.1 \mathrm{kcal} / \mathrm{mol}$ more stable than the corresponding singlet state. Although it has been proven that certain types of benzenoid polycyclic hydrocarbons, particularly those having high molecular weights, present an open-shell singlet ground state due to the extra stabilization energy associated with the recovery of one or more additional Clar's aromatic $\pi$-sextets, ${ }^{[29,30]}$ for comparison reasons we analyzed the Diels-Alder reaction involving these planar PAHs considering only their closed-shell singlet ground states. Since the biradical character is usually not located in the bay region, we expect for the studied Diels-Alder reaction a similar reactivity for open- and closed-shell singlets. ${ }^{[31]}$

We have explored both the endo and exo pathways of the Diels-Alder reaction between maleic anhydride and planar PAHs 1-10. In all cases, the [4+2]-cycloaddition reactions proceed concertedly via the TSs TS1-10 (see Figure 1 for the exo approach and Figure S1 in the Supporting Information for the endo pathway) from the corresponding initial reactant complexes (RC1-10) which lie ca. 8-12 kcal/mol below the separate reactants. The existence of these van der Waals complexes highlights the importance of including dispersion corrections in the study of the chemical reactivity of PAHs, as confirmed previously by us for buckybowls and fullerenes. ${ }^{[7,10-12,32]} \mathrm{A}$ closer examination of the fully optimized geometries of the corresponding concerted TSs (Figures 1 and S1) reveals that they are also highly synchronous (i.e. both $\mathrm{C} \cdots \mathrm{C}$ forming distances are equivalent) with the exception of the smaller members of both series ( 1 to 4), which are clearly more asynchronous. This behavior resembles that found for a number of Diels-Alder reactions ${ }^{[33]}$ including those involving bowl-shaped PAHs, ${ }^{[7]}$ whose TSs become also more and more synchronous with the increasing size of the system. 
SERIES A (3n-1)

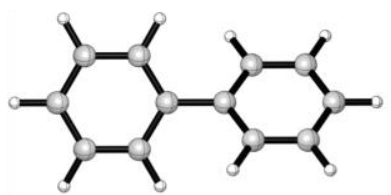

1 (biphenyl)

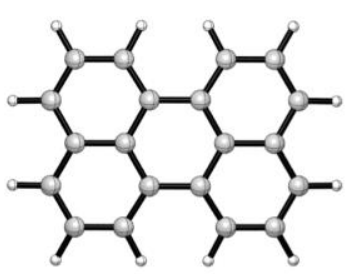

3 (perylene)

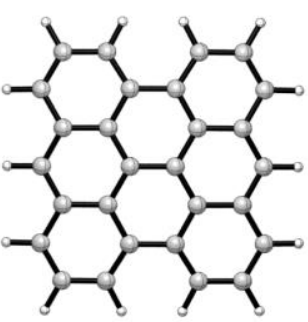

5 (bisanthene)

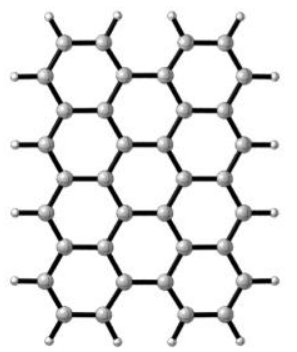

7 (peritetracene)

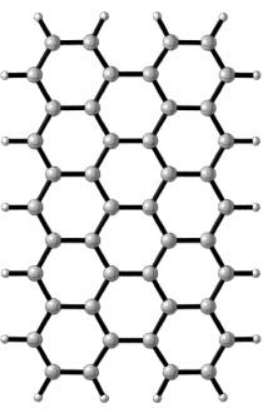

9 (peripentacene)
SERIES B (3n)

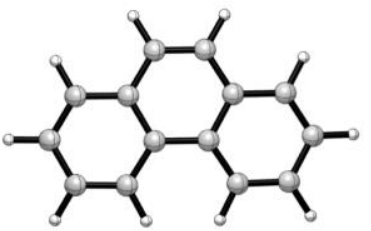

2 (phenanthrene)

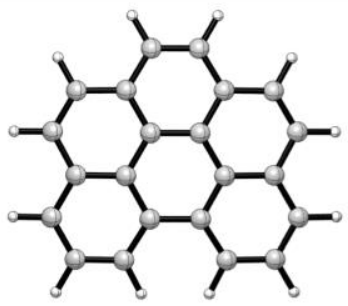

4 (benzoperylene)

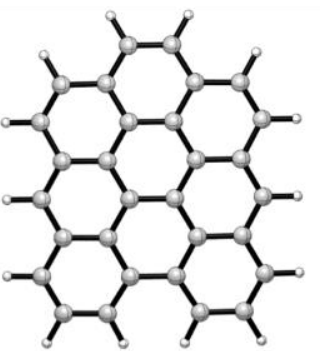

6 (benzobisanthene)

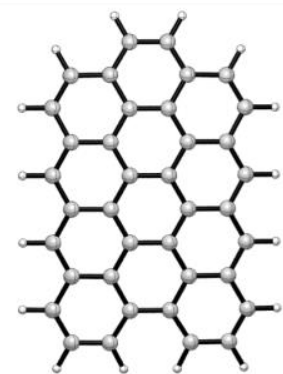

8 (dibenzoovalene)

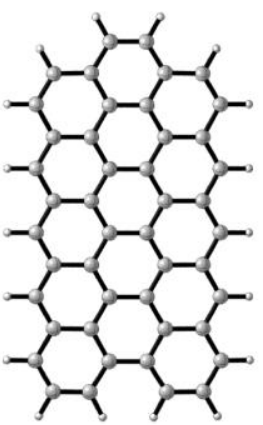

10 (tetrabenzoovalene)

Chart 1. Planar polycyclic aromatic hydrocarbons considered in this study. 


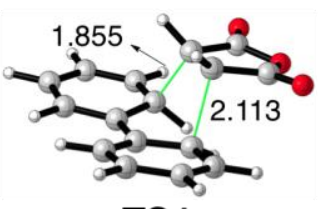

TS1

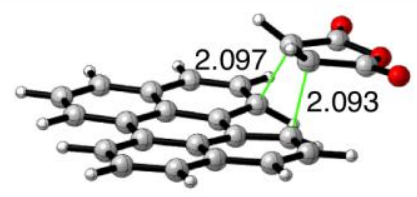

TS3

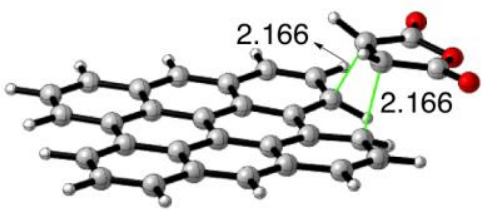

TS5

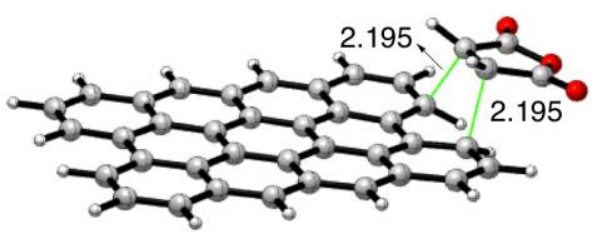

TS7

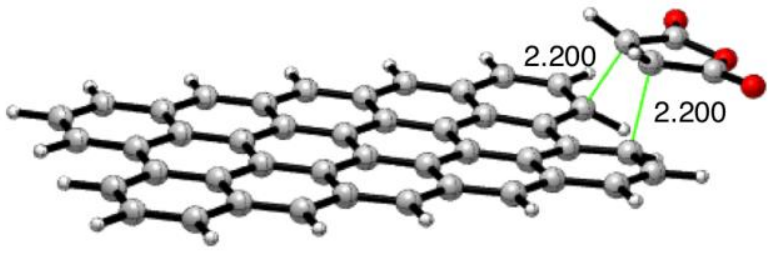

TS9

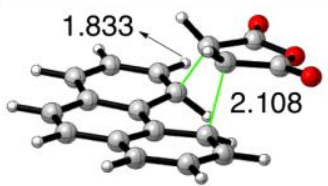

TS2

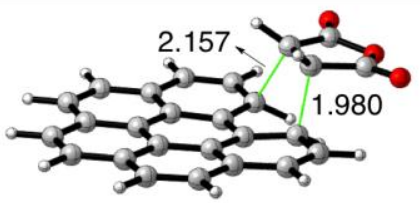

TS4

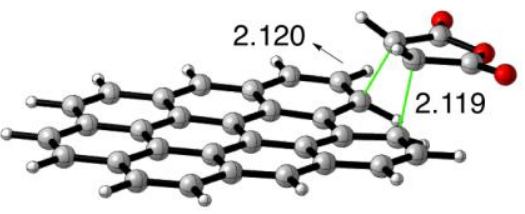

TS6

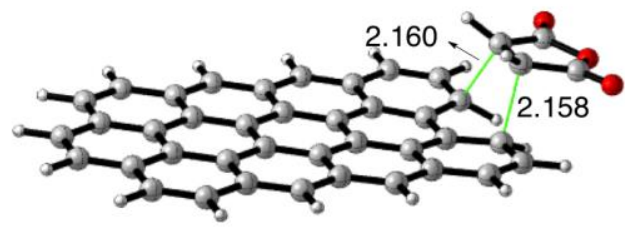

TS8

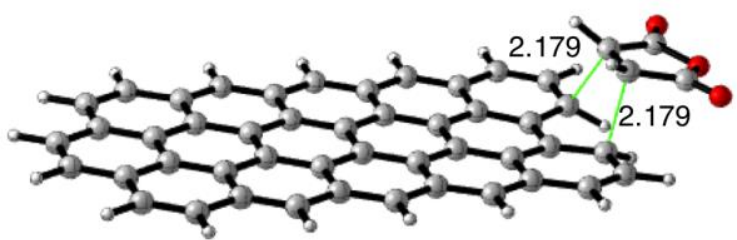

TS10

Figure 1. Fully optimized geometries (RI-BP86-D3/def2-SVP level) of the exo-transition states involved in the Diels-Alder cycloaddition reactions between maleic anhydride and planar PAHs 1-10 (for the corresponding endo-transition states, see Figure S1 in the Supporting Information). Bond distances are given in angstroms.

Table 1 gathers the activation barriers and reaction energies of the considered Diels-Alder cycloaddition reactions computed at the BP86-D3/def2-TZVPP//RI-BP86-D3/def2-SVP level. From the data in Table 1, it becomes clear that the exo-approach of maleic anhydride is, as expected, slightly thermodynamically favored over the endo-approach $\left(\Delta \Delta E_{\mathrm{R}} \approx 1 \mathrm{kcal} / \mathrm{mol}\right)$. From a kinetic point of view, although the endo-approach seems to be in most cases favored, the energy difference between both types of transition states can be considered as negligible $\left(\Delta \Delta E^{\dagger}<\right.$ $0.5 \mathrm{kcal} / \mathrm{mol}$ in most cases, see Table 1). Moreover, the relative activation barriers for the exo- 
approach computed from the respective initial reactant complexes are systematically lower than those computed the endo-pathway. Despite that, for both approaches, it was found that starting from either biphenyl or phenanthrene, the activation barrier of the process steadily decreases when the size of the system is increased for both series of planar PAHs. In addition, the transformation becomes more and more exothermic. Therefore, it is not surprising that a clear linear relationship between both computed energy values $\left(\Delta E^{\ddagger}\right.$ and $\left.\Delta E_{\mathrm{R}}\right)$ was found (correlation coefficient of 0.999 and 0.995 for the endo- and exo-approaches, respectively, see Figure 2). Interestingly, the slope of these linear correlations is really close to 0.5 , which indicates that the considered Diels-Alder reactions between maleic anhydride and planar PAHs follows the empirical relationship $\Delta E^{\ddagger}=\Delta E_{0}^{\ddagger}+1 / 2 \Delta E_{\mathrm{R}}$, given by Brønsted, Dimroth, Marcus, Bell-EvansPolanyi (also known as the Bema Hapothle relationship). ${ }^{[34]}$ This finding also resembles that found for the Diels-Alder reactions involving bowl-shaped $\mathrm{PAHs}^{[7]}$ and related planar and branched hydrocarbons, ${ }^{[35]}$ therefore indicating reactivity likeness of these species.

Table 1. Computed energies (in kcal/mol, BP86-D3/def2-TZVPP//RI-BP86-D3/def2-SVP level) for the Diels-Alder cycloaddition reactions between maleic anhydride and planar PAHs 1-10.

\begin{tabular}{|c|c|c|c|c|c|c|}
\hline Compound & Pathway & $\Delta \mathrm{E}_{R C}{ }^{[\mathrm{a}]}$ & $\Delta E^{\ddagger[b]}$ & $\Delta \mathbf{E}_{\mathbf{R}}{ }^{[\mathbf{c}]}$ & $\begin{array}{c}\Delta \Delta E_{\underline{T S}^{*}}(\text { endo- } \\
\text { exo })^{[\mathrm{d}]}\end{array}$ & $\Delta \Delta E_{R}(e n d o-e x o)^{[e]}$ \\
\hline \multirow[t]{2}{*}{1} & endo & -7.6 & 32.6 & 13.1 & 0.7 & 0.3 \\
\hline & exo & -8.5 & 32.7 & 12.7 & & \\
\hline \multirow[t]{2}{*}{2} & endo & -9.8 & 33.8 & 13.3 & 0.3 & 0.4 \\
\hline & exo & -8.7 & 32.4 & 12.9 & & \\
\hline \multirow[t]{2}{*}{3} & endo & -11.3 & 20.1 & -11.1 & -0.1 & 0.9 \\
\hline & exo & -9.5 & 18.4 & -12.0 & & \\
\hline \multirow[t]{2}{*}{4} & endo & -11.0 & 23.7 & -4.3 & -0.3 & 0.9 \\
\hline & exo & -9.2 & 22.2 & -5.2 & & \\
\hline \multirow[t]{2}{*}{5} & endo & -12.3 & 14.4 & -22.3 & -0.2 & 1.1 \\
\hline & exo & -10.5 & 12.8 & -23.4 & & \\
\hline 6 & endo & -11.7 & 18.4 & -15.0 & -0.1 & 1.0 \\
\hline
\end{tabular}




$\begin{array}{lcccccc}\mathbf{7} & \text { exo } & -8.7 & 15.5 & -16.0 & & \\ & \text { endo } & -12.9 & 12.4 & -26.5 & -0.4 & 1.1 \\ \mathbf{8} & \text { exo } & -11.1 & 11.0 & -27.6 & & 1.1 \\ & \text { endo } & -12.2 & 15.2 & -21.0 & -0.2 & 1.1 \\ & \text { exo } & -10.2 & 13.4 & -22.1 & & \\ \mathbf{1 0} & \text { endo } & -12.9 & 12.2 & -27.0 & -0.8 & 1.1 \\ & \text { exo } & -10.6 & 10.8 & -28.1 & & \end{array}$

[a] Reactant complex $(\mathbf{R C})$ energy: $\Delta E_{\mathrm{RC}}=E_{\mathrm{RC}}-E(\mathrm{PAH})-E$ (maleic anhydride). [b] Activation energy: $\Delta E^{*}=\mathrm{E}(\mathbf{T S})-\mathrm{E}(\mathbf{R C})$. [c] Reaction energy: $\Delta E_{\mathrm{R}}=E$ (cycloadduct) $-E(\mathrm{PAH})-E$ (maleic anhydride). [d] $\Delta E^{*}=\mathrm{E}(\mathrm{TS})-\mathrm{E}(\mathbf{R C}) \cdot[\mathrm{d}] \Delta \Delta E_{T S^{*}}($ endo-exo $)=\underline{E} \mathrm{E}($ TS -endo $)-\underline{E} \mathrm{E}($ TS-exo $) .[\mathrm{e}] \Delta \Delta E_{\mathrm{R}}=\Delta E_{\mathrm{R}}(\mathrm{endo})-$ $\Delta E_{\mathrm{R}}(\mathrm{exo})$.

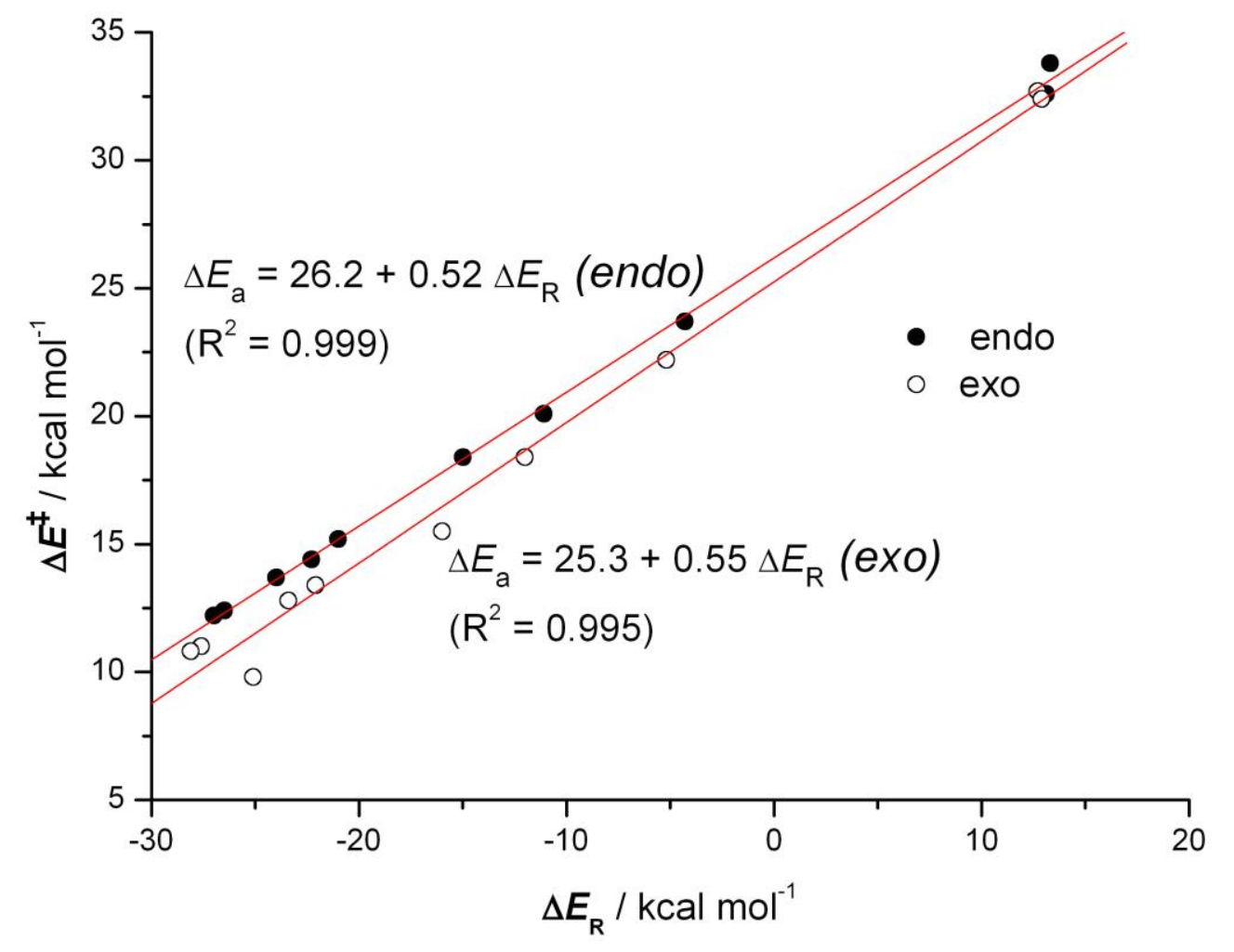

Figure 2. Plot of the reaction energies $\left(\Delta E_{\mathrm{R}}\right)$ vs energy barriers $\left(\Delta E^{\ddagger}\right)$ for the Diels-Alder cycloaddition reactions between maleic anhydride and the planar PAHs 1-10. Energy values (kcal/mol) were computed at the BP86-D3/def2-TZVPP//RI-BP86-D3/def2-SVP level.

The reduction in the energy barrier and the increase in the exothermicity of the reaction with the increase of the size of the PAHs can be qualitatively rationalized from Clar's $\pi$-sextet theory. ${ }^{[36]}$ Scheme 2 depicts the Clar structure for the planar PAHs 1-10. As can be seen, for the 
series $\mathrm{A}$, the number of $\pi$-sextets remains constant while the number of total six-membered rings increase by three from one member to the next member of the series. This implies a loss of aromaticity in all rings with increasing size and, particularly, in those located in the bay region for the larger PAHs. Consequently, the Diels-Alder cycloaddition reaction between maleic anhydride and PAHs is favored for the heavier PAH in series A. The trend followed by series B is the same but now all members have three $\pi$-sextets with the exception of phenanthrene (2). This is in line with the fact that when comparing two analogous members of the series (for instance, 3 and 4), the member of series A (two $\pi$-sextets) has a lower barrier and higher exothermicity than their counterpart in series B (three $\pi$-sextets). The only exception corresponds to compounds $\mathbf{1}$ and $\mathbf{2}$ that both have two $\pi$-sextets in the bay region, indicating that these rings have large aromaticity. Indeed, for these two systems, the barrier is the highest and the reaction is endothermic.

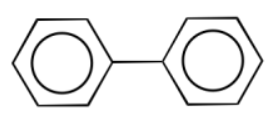

1

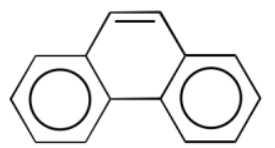

2

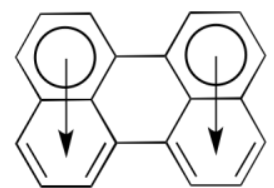

3

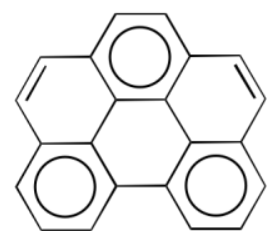

4

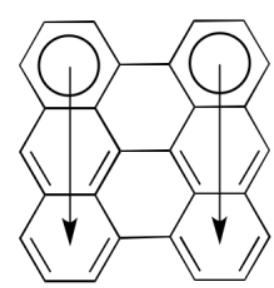

5

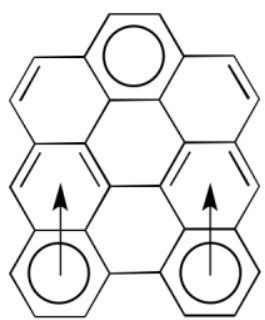

6

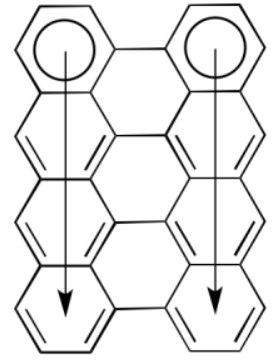

7

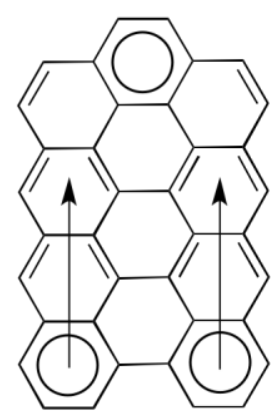

8

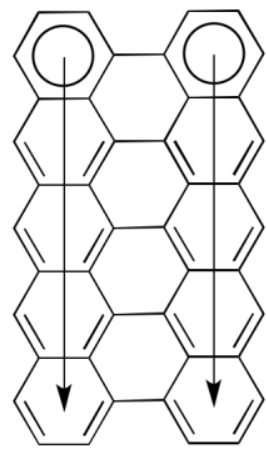

9

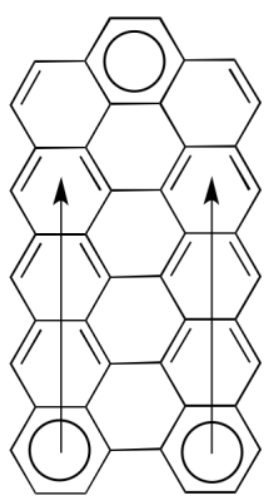

10

Scheme 2. The Clar structures for the planar PAHs 1-10. 
A remarkable difference is found in the reactivity of planar PAHs with respect to buckybowls. Whereas in the latter compounds both the activation barriers and reaction energies decrease linearly when the size of the system increases, ${ }^{[7]}$ the change in both energies in planar PAHs follows an exponential decay converging toward a final value which appears to be reached after ca. 48-52 carbon atoms (i.e. ca. 18-20 six-membered rings, exo-approach, Figure 3; for the similar endo-approach plots, see Figure S2 in the Supporting Information). This asymptotic behavior allows us to predict a limit for the Diels-Alder reaction involving the bay region of graphene of $\Delta E^{\ddagger} \approx 7-11 \mathrm{kcal} / \mathrm{mol} \Delta E_{\mathrm{R}} \approx-30 \mathrm{kcal} / \mathrm{mol}^{[37]}$

(a)

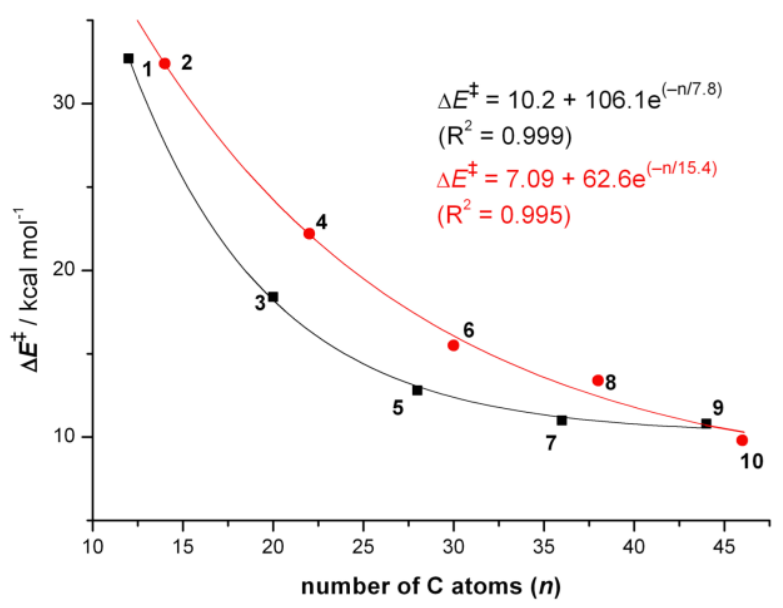

(b)

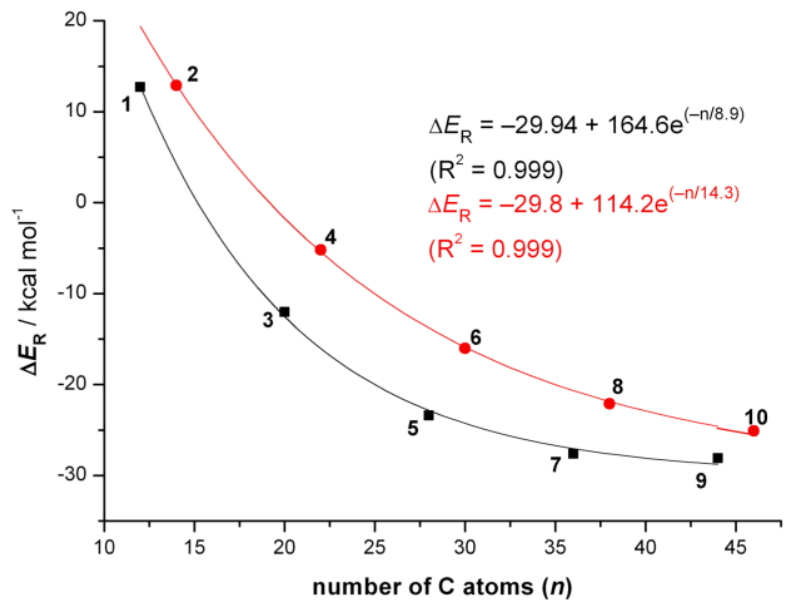

Figure 3. Plot of the activation barriers (a) and reaction energies (b) vs the total number of carbon atoms of the planar PAHs 1-10 (exo-approach). Energy values were computed at the BP86-D3/def2-TZVPP//RI-BP86-D3/def2-SVP level.

The Activation Strain Model (ASM) of reactivity was applied next to gain a deeper, quantitative understanding of the physical factors behind the above discussed Diels-Alder reactivity trend involving planar PAHs. To this end, we have selected for our analyses only the exo-pathway because this approach (i) is thermodynamically favored and there is no clear kinetic preference for the endo-approach (see Table 1), (ii) the reactivity trend (i.e. enhanced DielsAlder reactivity with the increasing size of the PAH) is exactly the same for both approaches, and (iii) the exo-pathway is experimentally followed to grow planar PAHs towards graphene derivatives (or towards nanotubes from bowl-shaped PAHs) by means of Diels-Alder 
reactions. ${ }^{[13]}$ The computed activation strain diagrams (ASD) from the initial stages of the processes to the corresponding TSs for all systems are given in the Supporting Information (Figure S3). Figure 4 shows only two representative cases for each series of PAHs, namely 1 and 7 for series A (Figure 4a) and $\mathbf{2}$ and $\mathbf{8}$ for series B (Figure 4b). As readily seen in Figure 4 (and Figure S3), all systems exhibit quite similar ASD. Thus, in all cases the interaction energy between the deformed reactants, measured by $\Delta E_{\text {int }}$, becomes slightly destabilizing at the early stages of the processes and inverts at a certain point along the reaction coordinate, after which this term becomes more and more stabilizing as one approaches the corresponding TS. This behavior resembles that found not only for the Diels-Alder reactions involving closely related bowl-shaped PAHs, ${ }^{[7]}$ but also in different pericyclic reactions such as $[3+2]$-cycloadditions, ${ }^{[38 a]}$ double-group transfer reactions, ${ }^{[38 \mathrm{~b}-\mathrm{d}]}$ Alder-ene reactions ${ }^{[38 \mathrm{e}]}$ or ene-ene-yne cyclizations, ${ }^{[38 \mathrm{f}]}$ therefore suggesting that the behavior of the $\Delta E_{\text {int }}$ term along the reaction coordinate is general in pericyclic reactions. ${ }^{[38 \mathrm{~g}]}$ Despite that, the stabilization provided by the interaction term cannot compensate the strong destabilizing effect of the deformation energy required to adopt the TS geometry $\left(\Delta E_{\text {strain }}\right)$. Therefore, the dominant factor controlling the barrier height of these [4+2]cycloaddition reactions is mainly the energy required to deform the reactants from their initial equilibrium geometries to the geometries they adopt in the corresponding TSs.

(a)

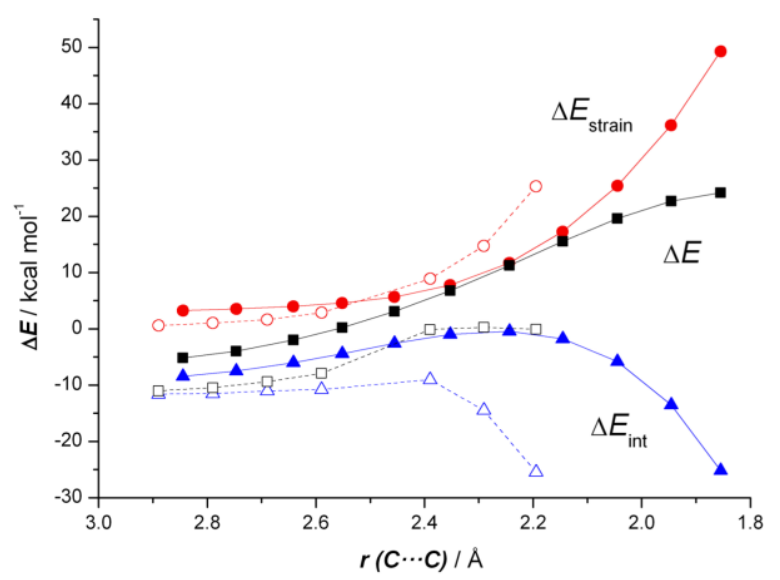

(b)

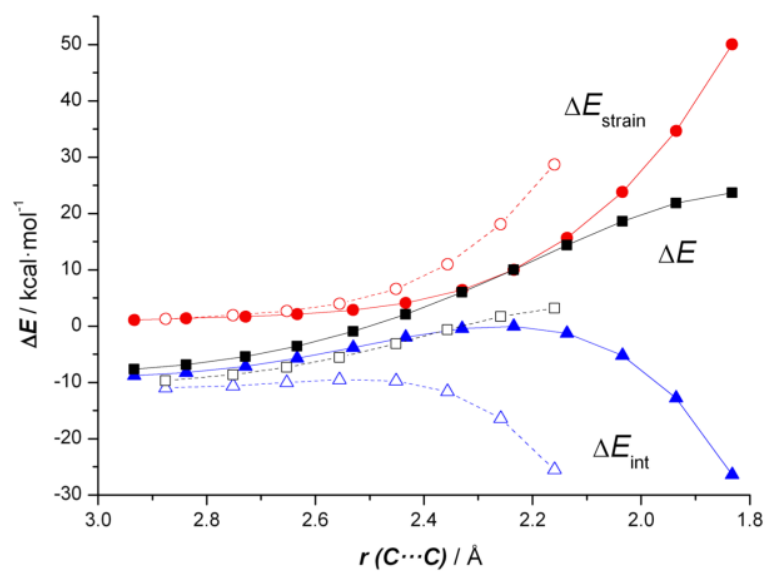

Figure 4. Activation-strain diagrams of the [4+2]-cycloaddition reaction between maleic anhydride (exo-approach) and 1 (Figure 4a, solid lines), 7 (Figure 4a, dotted lines), 2 (Figure 4b, solid lines) and 8 (Figure 4b, dotted lines) along the reaction coordinate projected onto the 
forming $\mathrm{C} \cdots \mathrm{C}$ bond distance. All data have been computed at the BP86-D3/def2-TZVPP//RIBP86-D3/def2-SVP level.

Significant differences can be observed when comparing the ASD of the smallest PAHs 1 and $\mathbf{2}$ with those of their heavier counterparts $\mathbf{7}$ and $\mathbf{8}$, respectively. As clearly seen in Figures 4a,b, the strain energy is not the factor responsible for the much lower activation barrier computed for the larger systems. Indeed, the $\Delta E_{\text {strain }}$ term is even less destabilizing for biphenyl or phenanthrene practically along the entire reaction coordinate. For instance, at the same $\mathrm{C} \cdots \mathrm{C}$ forming distance of $2.3 \AA$, a value of $\Delta E_{\text {strain }}=7.7 \mathrm{kcal} / \mathrm{mol}$ was computed for the phenanthrene system whereas a much higher value of $\Delta E_{\text {strain }}=15.2 \mathrm{kcal} / \mathrm{mol}$ was computed for the reaction involving compound dibenzoovalene 8 (Figure 4b). Interestingly, the less aromatic the 6-MRs in the bay region of the system, the more localized the double bonds and the larger the strain (compare strain of $\mathbf{1}$ and $\mathbf{7}$ or $\mathbf{2}$ and $\mathbf{8}$ ). At variance, the interaction energy, $\Delta E_{\mathrm{int}}$, between the deformed reactants is much stronger for the larger PAHs along the entire reaction coordinate. For instance, at the same $C \cdots \mathrm{C}$ forming distance of $2.3 \AA$, a value of $\Delta E_{\text {int }}=-0.3 \mathrm{kcal} / \mathrm{mol}$ was computed for the reaction involving phenanthrene whereas a much lower (i.e. more stabilizing) value of $\Delta E_{\mathrm{int}}=-14.3 \mathrm{kcal} / \mathrm{mol}$ was computed for the analogous process involving 8 (Figure $4 \mathrm{~b}$ ). Therefore, it can be concluded that the origin of the much lower activation barriers computed for the larger planar PAHs compared to their lighter congeners is found exclusively in the much stronger interaction energy between the deformed reactants along the entire reaction coordinate, which can compensate the higher deformation energy required to adopt the corresponding TS structures.

The Energy Decomposition Analysis (EDA) method was used next to further decompose the crucial $\Delta E_{\text {int }}$ term into different energy contributions. Figure 5 shows the EDA data for $\mathbf{1}$ vs 7 (Figure 5a) and for $\mathbf{2}$ vs $\mathbf{8}$ (Figure 5b) along the corresponding reaction coordinate again from the beginning of the process up to the respective TS geometries. In all cases, it becomes clear that despite the size of system, the $\Delta E_{\text {disp }}$ term remains practically constant and rather similar during 
the entire transformation and therefore is not decisive in making $\Delta E_{\text {int }}$ stronger for the larger PAHs. Similarly, the Pauli repulsion term, $\Delta E_{\text {Pauli, }}$ is also quite similar or even slightly less destabilizing for the smaller PAHs therefore indicating that the repulsion between closed-shells is not responsible for the computed difference in the interaction energy between the deformed reactants either. At variance, the orbital attractions measured by $\Delta E_{\text {orb }}$ as well as the electrostatic interactions, $\Delta V_{\text {elstat }}$ (although in a lesser extent), are clearly stronger (i.e. more stabilizing) in compounds 7 and $\mathbf{8}$ than in the smaller systems biphenyl and phenanthrene, respectively. For instance, at the same $\mathrm{C} \cdots \mathrm{C}$ forming distance of $2.3 \AA$, the computed $\Delta V_{\text {elstat }}=-37.1 \mathrm{kcal} / \mathrm{mol}$ and $\Delta E_{\text {orb }}=-31.8 \mathrm{kcal} / \mathrm{mol}$ values for the reaction involving phenanthrene are comparatively lower (i.e. weaker) than the respective values computed for dibenzoovalene $8\left(\Delta V_{\text {elstat }}=-42.4 \mathrm{kcal} / \mathrm{mol}\right.$ and $\left.\Delta E_{\text {orb }}=-50.3 \mathrm{kcal} / \mathrm{mol}\right)$. Therefore, it can be concluded that the stronger interaction between the deformed reactants along the entire reaction coordinate, which is responsible for the higher reactivity of large planar PAHs, derives mainly from the contributions of orbital and electrostatic (although in a lesser extent) attractions between the reactants, which become more and more stabilizing when the size of the PAH increases. Of course, the increase in both contributions follows a similar asymptotic behavior as the reaction barriers (see above). For instance, the change in the orbital term, $\Delta \Delta E_{\text {orb}}$, is much higher when going from phenanthrene 1 to benzobisanthene $6\left(\Delta \Delta E_{\text {orb }}=10.4 \mathrm{kcal} / \mathrm{mol}\right.$, at the same $\mathrm{C} \cdots \mathrm{C}$ distance of $\left.2.3 \AA\right)$ than when comparing the reactions involving $\mathbf{6}$ and $\mathbf{1 0}\left(\Delta \Delta E_{\text {orb }}=2.9 \mathrm{kcal} / \mathrm{mol}\right)$. 
(a)

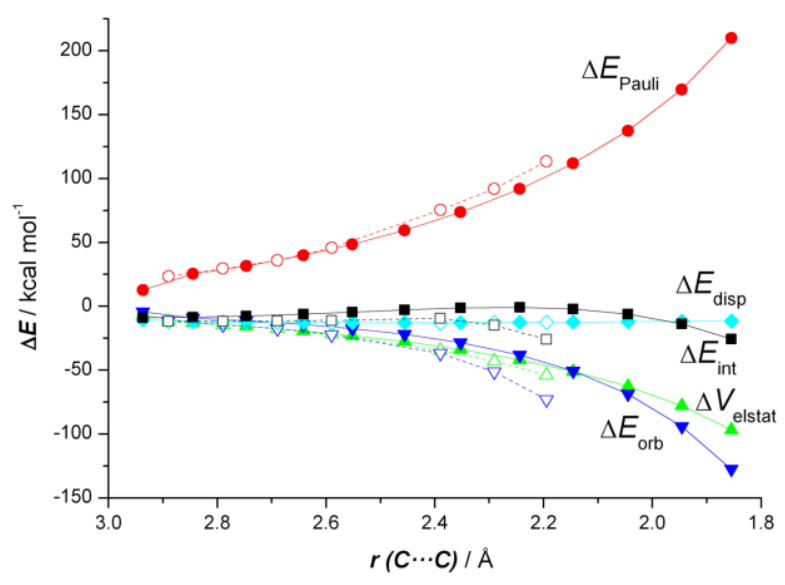

(b)

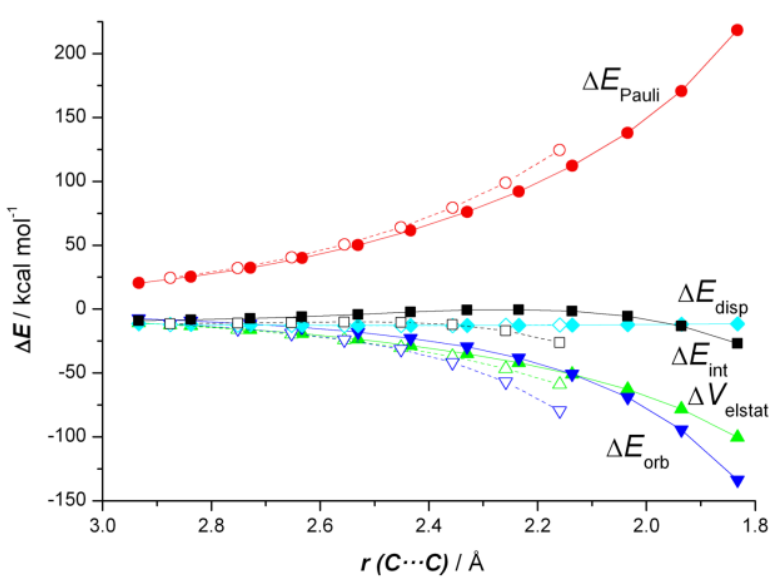

Figure 5. Decomposition of the interaction energy for the [4+2]-cycloaddition reactions between maleic anhydride (exo-approach) and 1 (Figure 4a, solid lines), 7 (Figure 4a, dotted lines), 2 (Figure 4b, solid lines) and 8 (Figure 4b, dotted lines) along the reaction coordinate projected onto the forming $\mathrm{C} \cdots \mathrm{C}$ bond distance. All data have been computed at the ZORA-BP86D3/TZ2P//RI-BP86-D3/def2-SVP level. Energies in kcal/mol and bond distances in $\AA$.

The origins of the stronger orbital interactions in compounds $\mathbf{7}$ and $\mathbf{8}$ (compared to $\mathbf{1}$ and $\mathbf{2}$, respectively) can be found by using the NOCV (Natural Orbital for Chemical Valence) method $^{[39]}$ in combination with the EDA. Thus, the EDA-NOCV approach, ${ }^{[40]}$ which provides pairwise energy contributions for each pair of interacting orbitals to the total bond energy, indicates that two main molecular orbital interactions dominate the total orbital interactions in these processes, namely the $\pi(\mathrm{PAH}) \rightarrow \pi^{*}$ (maleic anhydride) and the reverse $\pi$ (maleic anhydride) $\rightarrow \pi^{*}(\mathrm{PAH})$ interactions (see Figure 6). As expected for a normal electronic demand Diels-Alder process the $\pi(\mathrm{PAH}) \rightarrow \pi^{*}$ (maleic anhydride) interaction is clearly higher than the reverse interaction (i.e. $\left.\Delta E\left(\rho_{1}\right)>\Delta E\left(\rho_{2}\right)\right)$. Interestingly, both orbital interactions are clearly stronger in compound $\mathbf{8}$ than in $\mathbf{2}$ (see Figure 6 for the interactions occurring at the same $\mathrm{C} \cdots \mathrm{C}$ distance of $2.3 \AA$ ). Therefore, it can be concluded that the stronger orbital interactions in the heavier PAHs derive mainly from stronger $\pi(\mathrm{PAH}) \rightarrow \pi^{*}$ (maleic anhydride) interactions and, in a much lesser extent, from stronger reverse $\pi$ (maleic anhydride $) \rightarrow \pi^{*}(\mathrm{PAH})$ interactions as well. 
(a)

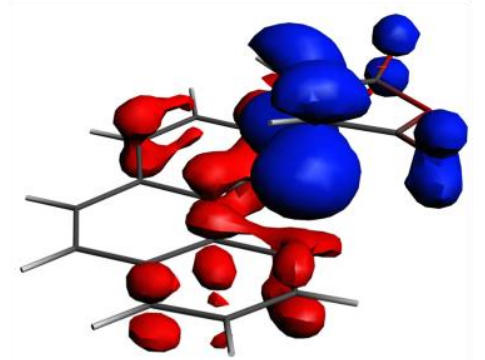

(b)
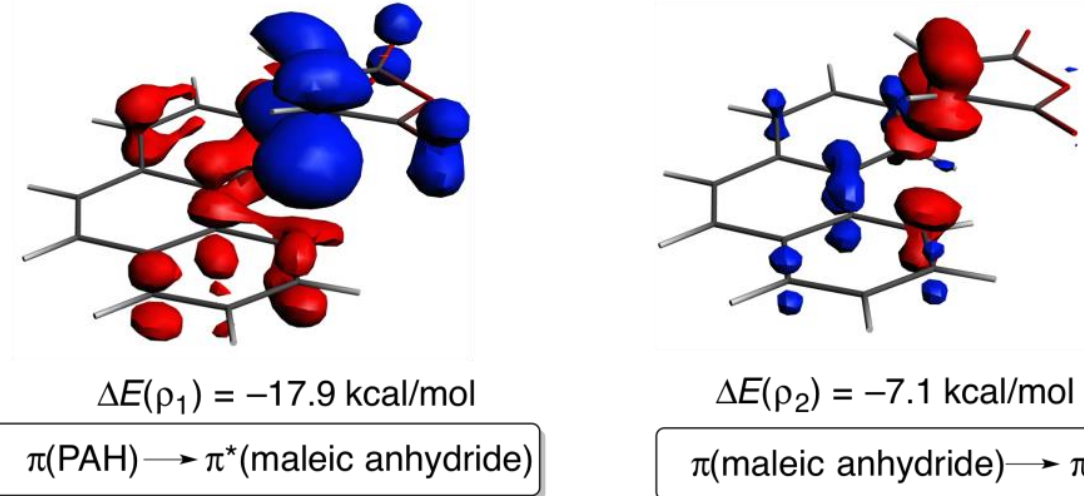

$$
\Delta E\left(\rho_{2}\right)=-7.1 \mathrm{kcal} / \mathrm{mol}
$$

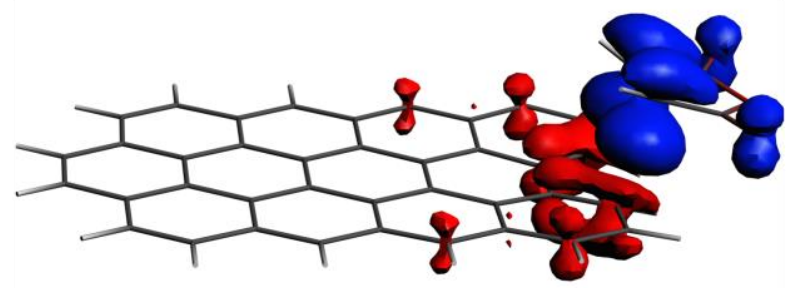

$\Delta E\left(\rho_{1}\right)=-29.3 \mathrm{kcal} / \mathrm{mol}$

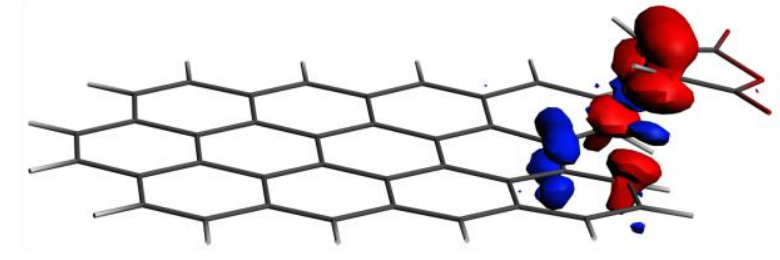

$\Delta E\left(\rho_{2}\right)=-12.3 \mathrm{kcal} / \mathrm{mol}$

Figure 6. Plot of the deformation densities $\Delta \rho$ of the pairwise orbital interactions between maleic anhydride and phenanthrene (a) and dibenzoovalene (b) and associated stabilization energies $\Delta E$ in $\mathrm{kcal} / \mathrm{mol}$. The color code of the charge flow is red $\rightarrow$ blue.

As commented in the introduction section, the energetic cost associated with simultaneously disrupting the local aromaticity of two benzene rings during the Diels-Alder reaction to the bay regions mainly dominates the energy barrier of the process. It was suggested that this cost is directly related to the difference in the aromatic stabilization energies ( $\triangle \mathrm{ASE}$ ) between the initial reactant and the corresponding cycloadduct. ${ }^{[13]}$ For this reason, we finally were curious to assess the relationship between the change in aromaticity and the computed activation barriers. To this end, the ASE values of both the initial reactants and the corresponding cycloadducts were quantitatively computed by applying the so-called "isomerization method" (ISE) developed by Schleyer and Pühlhofer. ${ }^{[41]}$ This approach is based on the differences between the total energies computed for only two species, namely a methyl derivative of the aromatic system and its nonaromatic exocyclic methylene isomer (Scheme 2). 
<smiles>Cc1ccc2c3ccc(C)c4cccc(c5cccc1c52)c43</smiles>

$1-10(\mathrm{Me})$

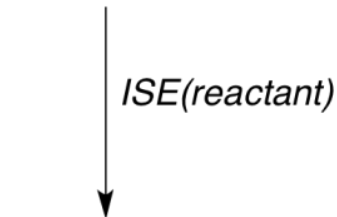<smiles>C=C1C=CC(c2ccc3ccc(=C)c4cccc2c34)=CC1C</smiles>

1-10(iso)<smiles>C=C1C(C)=CC2c3c4c1cccc1c5cccc(c-4c3-5)C=CC2C2C(=O)OC(=O)C12</smiles>

1-10-cycloadduct(Me) ISE(cycloadduct)

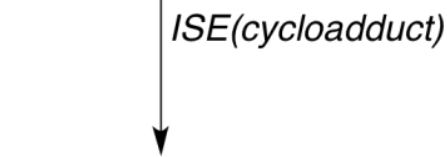

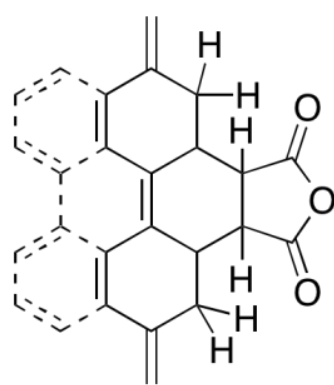

1-10-cycloadduct(iso)

Scheme 2. Compounds used to quantify the Aromatic Stabilization Energies by means of the isomerization method.

Table 12. Computed energies (in kcal/mol, BP86-D3/def2-TZVPP//RI-BP86-D3/def2-SVP level) for the Diels-Alder cycloaddition reactions between maleic anhydride and planar PAHs belonging to series $\mathrm{B}$.

\begin{tabular}{|c|c|c|c|}
\hline Compound & ISE $(\text { reactant })^{[\mathrm{a}]}$ & ISE $(\text { cycloadduct })^{[b]}$ & $\Delta \mathrm{ISE}^{[\mathrm{c}]}$ \\
\hline 2 & 70.3 & 6.0 & 64.3 \\
\hline 4 & 58.1 & 11.5 & 46.6 \\
\hline 6 & 52.0 & 12.4 & 39.6 \\
\hline 8 & 49.4 & 12.4 & 37.1 \\
\hline
\end{tabular}

[a] ISE $($ reactant $)=E($ iso $)-E(\mathrm{Me})$. [b] ISE(cycloadduct $)=E($ cycloadduct-iso $)-E$ (cycloadduct$\mathrm{Me}) .[\mathrm{c}] \Delta \mathrm{ISE}=\mathrm{ISE}($ reactant $)-\mathrm{ISE}($ cycloadduct $)$ 
From the data in Table 2, it is confirmed that the six-membered rings in the bay region of the reactants of series B exhibit a clear aromatic character (ISE ranging from 24 to $35 \mathrm{kcal} / \mathrm{mol}$ per benzenoid ring) whereas much lower ISE values (ca. 6-7 kcal/mol per benzenoid ring) were computed for the corresponding nonaromatic cycloadducts. As expected from Clar's $\pi$-sextet theory, the strength of aromaticity decreases with the size of the PAH for both series of compounds. For instance, whereas a value of ISE $=70.3 \mathrm{kcal} / \mathrm{mol}$ (i.e. ca. $35 \mathrm{kcal} / \mathrm{mol}$ per benzenoid ring) was computed for the phenanthrene derivative (a similar value of $33.2 \mathrm{kcal} / \mathrm{mol}$ was computed for benzene by Schleyer and Pühlhofer),${ }^{[41]}$ the aromaticity strength of compounds $\mathbf{8}$ or $\mathbf{1 0}$ are comparatively lower (ISE ca. $25 \mathrm{kcal} / \mathrm{mol}$ ). A similar trend is observed when considering the change in aromaticity measured by the $\Delta$ ISE values (see Table 2). Therefore, these data qualitatively support the suggestion that the variation of the aromaticity is related to the barrier heights of the considered Diels-Alder cycloadditions. Moreover, linear relationships were found when plotting both parameters ( $\Delta E^{*}$ vs ISE and $\Delta \mathrm{ISE}$, Figure 7) which confirms that the variation of the aromaticity strengths during the reaction can directly correlated with the corresponding reaction barriers.

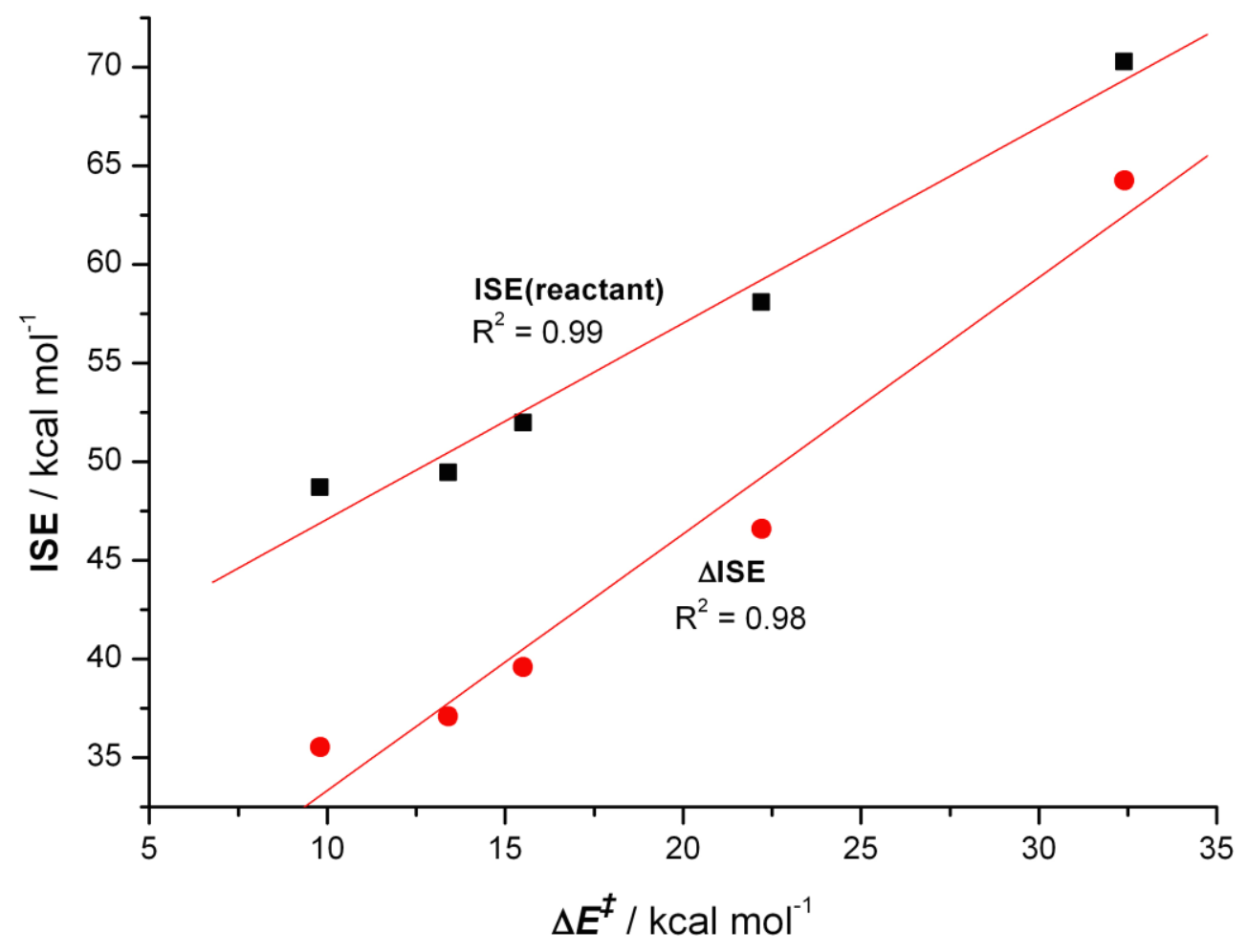


Figure 7. Plot energy barriers $\left(\Delta E^{\ddagger}\right.$, exo-approach) versus the aromaticity stabilization energy of reactants (ISE, black squares) and the change in the aromaticity strength ( $\Delta \mathrm{ISE}$, red circles) for the Diels-Alder cycloaddition reactions between maleic anhydride and the planar PAHs 2-10. Energy values $(\mathrm{kcal} / \mathrm{mol})$ were computed at the BP86-D3/def2-TZVPP//RI-BP86-D3/def2-SVP level.

\section{Conclusions}

From the computational study reported herein, the following conclusions can be drawn: (i) starting from biphenyl or phenanthrene, the energy barrier of the Diels-Alder reaction of maleic anhydride to the bay region of planar PAHs steadily decreases when the size of the PAH is increased; in addition, the process becomes more and more exothermic. (ii) At variance with buckybowls where the barrier heights of related Diels-Alder reactions decreases linearly with the size of the system, the change in either the activation barriers or the reaction energies in planar PAH follows an exponential behavior reaching its maximum around 18-20 benzenoid rings in the structure. This asymptotic behavior allows us to extrapolate the values for a similar process involving the bay region of graphene: $\Delta E^{*} \approx 7-11 \mathrm{kcal} / \mathrm{mol}$ and $\Delta E_{\mathrm{R}} \approx-30 \mathrm{kcal} / \mathrm{mol}$. (iii) Although the energy required to deform the reactants from their equilibrium geometries to the geometry they adopt in the corresponding TSs controls the barrier heights of the processes, the stronger interaction energy between the deformed reactants along the entire reaction coordinate in larger PAHs is the major factor responsible for the observed Diels-Alder reactivity trend. (iv) This is the result of higher orbital and electrostatic (although in a lesser extent) interactions between the deformed reactants. (v) The stronger orbital interactions are mainly the result of much higher $\pi(\mathrm{PAH}) \rightarrow \pi^{*}$ (maleic anhydride) interaction in the heavier planar PAHs. (vi) Finally, it is quantitatively confirmed by means of the isomerization method that the variation of the aromaticity strengths during the reaction can be directly correlated with the corresponding reaction barriers. 


\section{Acknowledgments}

We are grateful for financial support from the Spanish MINECO-FEDER (Grants CTQ201344303-P and CTQ2014-51912-REDC to I. F. and CTQ2014-54306-P to M. S.), Fundación BBVA, and Catalan DIUE (projects 2014SGR931 and XRQTC to M. S.). .). Support for the research of M. S. was received through the ICREA Academia 2014 prize of the Catalan DIUE. The FEDER grant UNGI10-4E-801 (European Fund for Regional Development) has also funded this research. Y. G.-R. acknowledges the MINECO for an FPI grant.

\section{Supporting Information Available}

Figures S1-S3, Cartesian coordinates and total energies of all the stationary points discussed in the text.

\section{References and Notes}

[1]. E. Clar in Polycyclic Hydrocarbons, Academic Press: New York, 1964.

[2]. R. G. Harvey in Polycyclic Aromatic Hydrocarbons, Wiley-VCH: New York, N.Y., 1997.

[3]. For a recent review: L. T. Scott, Chem. Soc. Rev. 2015, 44, 6464.

[4]. M. A. Petrukhina, L. T. Scott, Eds. Fragments of Fullerenes and Carbon Nanotubes: Designed Synthesis, Unusual Reactions, and Coordination Chemistry; John Wiley \& Sons: Hoboken, 2011.

[5]. For recent reviews, see: a) I. J. Keyte, R. M. Harrison, G. Lammel, Chem. Soc. Rev. 2013, 42, 9333; b) K-H. Kim, S. A. Jahan, E. Kabir, R. J. C. Brown, Environ Int. 2013, 60, 71.

[6]. Polycyclic Arenes and heteroarenes, Synthesis, properties and applications, Q. Miao, ed., Wiley-VCH: Weinheim, 2015.

[7]. Y. García-Rodeja, M. Solà, F. M. Bickelhaupt, I. Fernández, Chem. Eur. J. 2016, 22, 1368.

[8]. a) F. M. Bickelhaupt, J. Comput. Chem. 1999, 20, 114. For reviews, see: b) W.-J. van Zeist, F. M. Bickelhaupt, Org. Biomol. Chem. 2010, 8, 3118; c) I. Fernández, F. M. Bickelhaupt, Chem. Soc. Rev. 2014, 43, 4953; d) L. P. Wolters, F. M. Bickelhaupt, WIREs Comput. Mol. Sci. 
2015, 5, 324. See also, e) I. Fernández, in Discovering the Future of Molecular Sciences; B. Pignataro, Ed.; pp. 165-187, Wiley-VCH: Weinheim, 2014.

[9]. a) M. von Hopffgarten, G. Frenking, WIREs Comput. Mol. Sci. 2012, 2, 43; b) The EDA Perspective of Chemical Bonding" in The Chemical Bond - Fundamental Aspects of Chemical Bonding (Eds.: G. Frenking, S. Shaik), G. Frenking, F. M. Bickelhaupt, pp. 121-158, WileyVCH, Weinheim 2014.

[10]. I. Fernández, M. Solà, F. M. Bickelhaupt, Chem. Eur. J. 2013, 19, 7416.

[11]. I. Fernández, M. Solà, F. M. Bickelhaupt, J. Chem. Theory Comput. 2014, 10, 3863.

[12]. F. M. Bickelhaupt, M. Solà, I. Fernández, Chem. Eur. J. 2015, 21, 5760.

[13]. E. H. Fort, P. M. Donovan, L. T. Scott, J. Am. Chem. Soc. 2009, 131, 16006.

[14]. E. H. Fort, M. S. Jeffreys, L. T. Scott, Chem. Commun. 2012, 48, 8102.

[15]. E. H. Fort, L. T. Scott, Angew. Chem. Int. Ed. 2010, 49, 6626.

[16]. E. Clar, M. Zander, J. Chem. Soc. 1957, 4616.

[17]. Gaussian 03, Revision D. 01, M. J. Frisch, G. W. Trucks, H. B. Schlegel, G. E. Scuseria, M. A. Robb, J. R. Cheeseman, J. A. Montgomery, Jr., T. Vreven, K. N. Kudin, J. C. Burant, J. M. Millam, S. S. Iyengar, J. Tomasi, V. Barone, B. Mennucci, M. Cossi, G. Scalmani, N. Rega, G. A. Petersson, H. Nakatsuji, M. Hada, M. Ehara, K. Toyota, R. Fukuda, J. Hasegawa, M. Ishida, T. Nakajima, Y. Honda, O. Kitao, H. Nakai, M. Klene, X. Li, J. E. Knox, H. P. Hratchian, J. B. Cross, V. Bakken, C. Adamo, J. Jaramillo, R. Gomperts, R. E. Stratmann, O. Yazyev, A. J. Austin, R. Cammi, C. Pomelli, J. W. Ochterski, P. Y. Ayala, K. Morokuma, G. A. Voth, P. Salvador, J. J. Dannenberg, V. G. Zakrzewski, S. Dapprich, A. D. Daniels, M. C. Strain, O. Farkas, D. K. Malick, A. D. Rabuck, K. Raghavachari, J. B. Foresman, J. V. Ortiz, Q. Cui, A. G. Baboul, S. Clifford, J. Cioslowski, B. B. Stefanov, G. Liu, A. Liashenko, P. Piskorz, I. Komaromi, R. L. Martin, D. J. Fox, T. Keith, M. A. Al-Laham, C. Y. Peng, A. Nanayakkara, M. Challacombe, P. M. W. Gill, B. Johnson, W. Chen, M. W. Wong, C. Gonzalez, and J. A. Pople, Gaussian, Inc., Wallingford CT, 2004.

[18]. R. Ahlrichs, M. Bär, M. Häser, H. Horn, C. Kölmel, Chem. Phys. Lett. 1989, 162, 165.

[19]. a) A. D. Becke, Phys. Rev. A 1988, 38, 3098; b) J. P. Perdew, Phys. Rev. B 1986, 33, 8822.

[20]. F. Weigend, R. Ahlrichs, Phys. Chem. Chem. Phys. 2005, 7, 3297.

[21]. S. Grimme, J. Antony, S. Ehrlich, H. Krieg, J. Chem. Phys. 2010, 132, 154104.

[22]. K. Eichkorn, O. Treutler, H. Öhm, M. Häser, R. Ahlrichs, Chem. Phys. Lett. 1995, 242, 652. 
[23]. C. González, H. B. Schlegel, J. Phys. Chem. 1990, 94, 5523.

[24]. Selected examples from the Houk group: a) K. N. Houk, R, W. Gandour, R. W. Strozier, N. G. Rondan, L. A. Paquette, J. Am. Chem. Soc. 1979, 101, 6797; b) D. H. Ess, K. N. Houk, J. Am. Chem. Soc. 2007, 129, 10646; c) D. H. Ess, K. N. Houk, J. Am. Chem. Soc. 2008, 130, 10187; d) S. Osuna and K. N. Houk, Chem. Eur. J. 2009, 15, 13219; e) D. N. Kamber, L. A. Nazarova, Y. Liang, S. A. Lopez, D. M. Patterson, H.-W. Shih, K. N. Houk, J. A. Prescher, J. Am. Chem. Soc. 2013, 135, 13680; f) Y. Cao, Y. Liang, L. Zhang, S. Osuna, A.-L. M. Hoyt, A. L. Briseno, K. N. Houk, J. Am. Chem. Soc. 2014, 136, 10783; g) J. M. Medina, J. L. Mackey, N. K. Garg, K. N. Houk, J. Am. Chem. Soc. 2014, 136, 15798.

[25]. E. J. Baerends, J. Autschbach, A. Berces, J. A. Berger, F. M. Bickelhaupt, C. Bo, P. L. de Boeij, P. M. Boerrigter, L. Cavallo, D. P. Chong, L. Deng, R. M. Dickson, D. E. Ellis, M. van Faassen, L. Fan, T. H. Fischer, C. Fonseca Guerra, S. J. A. van Gisbergen, J. A. Groeneveld, O. V. Gritsenko, M. Grüning, F. E. Harris, P. van den Hoek, C. R. Jacob, H. Jacobsen, L. Jensen, E. S. Kadantsev, G. van Kessel, R. Klooster, F. Kootstra, E. van Lenthe, D. A. McCormack, A. Michalak, J. Neugebauer, V. P. Nicu, V. P. Osinga, S. Patchkovskii, P. H. T. Philipsen, D. Post, C. C. Pye, W. Ravenek, P. Romaniello, P. Ros, P. R. T. Schipper, G. Schreckenbach, J. Snijders, M. Solà, M. Swart, D. Swerhone, G. Te Velde, P. Vernooijs, L. Versluis, L. Visscher, O. Visser, F. Wang, T. A. Wesolowski, E. M. van Wezenbeek, G. Wiesenekker, S. K. Wolff, T. K. Woo, A. L. Yakovlev, T. Ziegler, Computer Code ADF 2013.01; Scientific Computing and Modeling NV: Amsterdam, The Netherlands http://www.scm.com.

[26]. J. G. Snijders, E. J. Baerends, P. Vernoojs, At. Data Nucl. Data Tables 1981, 26, 483.

[27]. J. Krijn, E. J. Baerends, Fit Functions in the HFS-Method, Internal Report (in Dutch), Vrije Universiteit Amsterdam, The Netherlands, 1984.

[28]. a) E. van Lenthe, E. J. Baerends, J. G. Snijders, J. Chem. Phys. 1993, 99, 4597; b) E. van Lenthe, E. J. Baerends, J. G. Snijders, J. Chem. Phys. 1994, 101, 9783; c) E. van Lenthe, A. Ehlers, E. J. Baerends, J. Chem. Phys. 1999, 110, 8943.

[29]. For a review on the ground states of PAHs, see: Z. Sun, Z. Zeng, J. Wu, Chem. Asian J. 2013, 8, 2894 and references therein.

[30]. For calculations on the ground states of acenes, see: a) D. Jiang, S. Dai, Chem. Phys. Lett. 2008, 466, 72; b) M. Bendikov, H. M. Doung, K. Starkey, K. N. Houk, E. A. Carter, F. Wudl, J. Am. Chem. Soc. 2004, 126, 7416; c) J. Poater, J. M. Bofill, P. Alemany and M. Solà, J. Phys. Chem. A, 2005, 109, 10629; d) H. F. Bettinger, C. Tönshoff, M. Doerr, E. Sanchez-Garcia, J. Chem. Theory Comput. 2016, 12, 305. 
[31]. a) Z. Sun, S. Lee, K. H. Park, X. Zhu, W. Zhang, B. Zheng, P. Hu, Z. Zeng, S. Das, Y. Li, C. Chi, R.-W. Li, K.-W. Huang, J. Ding, D. Kim and J. Wu, J. Am. Chem. Soc. 2013, 135, 18229; b) A. Shimizu, Y. Hirao, T. Kubo, M. Nakano, E. Botek and B. Champagne, AIP Conf. Proc. 2012, 1504, 399.

[32]. a) S. Osuna, M. Swart, M. Solà, J. Phys. Chem. A 2011, 115, 3491; b) M. Garcia-Borràs, J. M. Luis, M. Swart, M. Solà, Chem. Eur. J. 2013, 19, 4468.

[33]. S. M. Bachrach, P. B. White, J. Mol. Struct.: THEOCHEM 2007, 819, 72.

[34]. W. P. Jencks, Chem. Rev. 1985, 85, 511.

[35]. A. E. Hayden, K. N. Houk, J. Am. Chem. Soc. 2009, 131, 4084.

[36]. a) E. Clar, The Aromatic Sextet, Wiley, NewYork, 1972; b) M. Solà, Front. Chem. 2013, 1,22 .

[37]. For a computational study of the regioselectivity of the Diels-Alder reactions of graphene using related model compounds, see: Y. Cao, S. Osuna, Y. Liang, R. H. Haddon, K. N. Houk, J. Am. Chem. Soc. 2013, 135, 17643.

[38]. a) I. Fernández, F. P. Cossío, F. M. Bickelhaupt, J. Org. Chem. 2011, 76, 2310; b) I. Fernández, F. M. Bickelhaupt, F. P. Cossío, Chem. Eur. J. 2009, 15, 13022; c) O. Nieto Faza, C. Silva López, I. Fernández, J. Org. Chem. 2013, 78, 5669; d) I. Fernández, F. P. Cossío, J. Comput. Chem. 2016, doi: 10.1002/jcc.24317; e) I. Fernández, F. M. Bickelhaupt, J. Comput. Chem. 2012, 33, 509; f) I. Fernández, F. M. Bickelhaupt, F. P. Cossío, Chem. Eur. J. 2014, 20, 10791; g) I. Fernández, Phys. Chem. Chem. Phys. 2014, 16, 7662.

[39]. M. Mitoraj, A. Michalak, J. Mol. Model. 2007, 13, 347.

[40]. M. P. Mitoraj, A. Michalak, T. Ziegler, J. Chem. Theory Comput. 2009, 5, 962.

[41]. P. v. R. Schleyer, F. Pühlhofer, Org. Lett., 2002, 4, 2873. 


\section{Graphical Abstract}

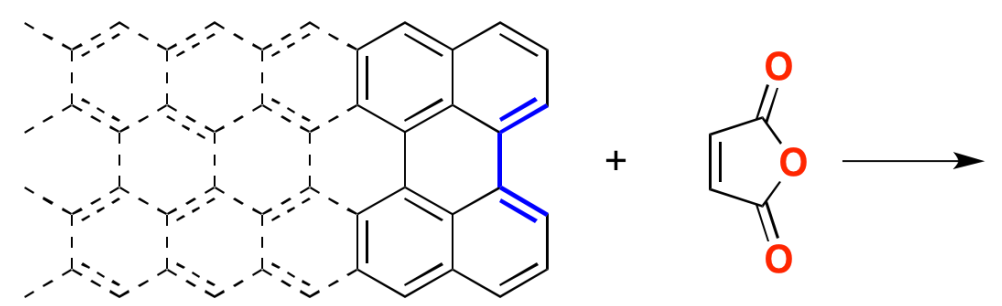

Diels-Alder reactivity in the bay region

Larger system, better reactivity. The Diels-Alder reactivity of maleic anhydride to the bay regions of planar polycyclic aromatic hydrocarbons increases with the size of the system. The origins of this reactivity trend are analyzed in detail through density functional calculations. 